\title{
Cycling of the Mechanical Ventilator Breath
}

\author{
Michael A Gentile RRT FAARC
}

\author{
Introduction \\ Cycling Mechanisms \\ Pressure Cycling \\ Time Cycling \\ Volume Cycling \\ Flow Cycling \\ Premature Cycling \\ Delayed Cycling \\ Expiratory Asynchrony \\ Summary
}

\begin{abstract}
Patient-ventilator interaction is a key element in optimizing mechanical ventilation. The change from inspiration to expiration is a crucial point in the mechanically ventilated breath, and is termed "cycling." Patient-ventilator asynchrony may occur if the flow at which the ventilator cycles to exhalation does not coincide with the termination of neural inspiration. Ideally, the ventilator terminates inspiratory flow in synchrony with the patient's neural timing, but frequently the ventilator terminates inspiration either early or late. Most current mechanical ventilators include adjustable cycling features that, when used in conjunction with waveform graphics, can enhance patient-ventilator synchrony. Key words: asynchrony; patient-ventilator interaction; pressure-support ventilation; cycling criterion; expiratory asynchrony; premature cycling; delayed cycling. [Respir Care 2011;56(1):52-57. (c) 2011 Daedalus Enterprises]
\end{abstract}

\section{Introduction}

The goals of mechanical ventilatory support are to provide unloading of the respiratory muscles and medical gas to sustain life. Patient-ventilator interaction is complex

Michael A Gentile RRT FAARC is affiliated with the Division of Pulmonary and Critical Care Medicine, Duke University Medical Center, Durham, North Carolina.

The author has disclosed no conflicts of interest.

Mr Gentile presented a version of this paper at the 46th RESPIRATORY CARE Journal Conference, "Patient-Ventilator Interaction," held March 1921, 2010, in Cancún, Quintana Roo, Mexico.

Correspondence: Michael A Gentile RRT FAARC, Division of Pulmonary and Critical Care Medicine, Box 3046, Duke University Medical Center, Durham NC 27710. E-mail: michael.gentile@ duke.edu. and multifactorial, as it is dependent upon respiratory system conditions, various disease states, neural function, and clinical input. ${ }^{1,2}$ When optimized, patient-ventilator interaction can provide patient comfort during positive-pressure breaths. However, harmful patient-ventilator interaction can occur if the patient and the ventilator are not synchronous. This asynchrony may lead to increased respiratory muscle work load, elevated sedation need, longer duration of ventilation, higher oxygen consumption, and potentially injurious pulmonary pressures. ${ }^{3-6}$ Patients with greater asynchrony have worse outcomes and longer duration of ventilation, ${ }^{3-7}$ so optimizing and maintaining synchrony is very important.

The mechanical ventilator breath can be separated into 2 parts: inspiratory phase and expiratory phase. At the end of inspiration, gas flow ceases, and the breath is switched into exhalation. This transition point from the inspiratory phase to the expiratory phase is termed "cycling." Simply, 
the inspiratory phase is cycled into expiration when gas flow ceases from the mechanical ventilator and expiratory flow begins. Many settings on the mechanical ventilator induce cycling, such as preset volume, time, and flow. Recent advances in mechanical ventilator design allow clinicians to have a greater role in cycling assessment and manipulation. Cycling has also been termed "expiratory trigger," "inspiratory termination criteria," and "inspiratory flow termination."

While much attention has focused on the inspiratory phase, the purpose of this report is to examine the cycling and expiratory phase of the mechanical ventilator breath. Other important topics include premature cycling, delayed cycling, and the ramifications of expiratory asynchrony.

\section{Cycling Mechanisms}

The cycling of a mechanical ventilator breath occurs after a set value is reached. These values are often referred to as "cycle variables." 8 All mechanical ventilator breath types are governed by cycling variables. Four variables are used to determine when to cycle to exhalation: pressure, time, volume, and flow.

\section{Pressure Cycling}

When a certain pressure threshold is reached, inspiration is cycled into exhalation. The most common application for pressure cycling is for alarm settings. If a patient becomes extremely asynchronous or coughs, the highpressure alarm may be triggered and the inspiratory phase ends, resulting in exhalation. Pressure cycling can be viewed as a safety feature to avoid elevated and sustained inspiratory pressure.

\section{Time Cycling}

Time cycling indicates that the mechanical ventilator breath switches from inspiration to expiration after a set time threshold is reached. This can be accomplished by setting the respiratory rate, inspiratory time, or inspiratoryexpiratory ratio. Many ventilators terminate the inspiratory phase after a certain timeframe: typically $3-5$ seconds.

\section{Volume Cycling}

With conventional volume-targeted breaths, inspiration stops once the target volume is delivered. The ventilator cycles to expiration once a set tidal volume has been delivered. Volume cycling is only adjustable as the clinician sets a tidal volume to be delivered or a maximum tidal volume alarm setting.

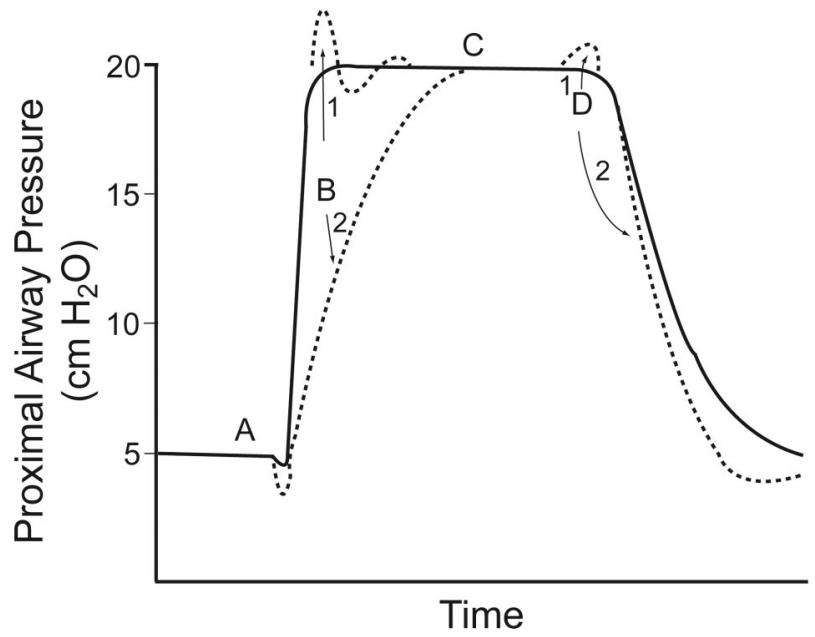

Fig. 1. Characteristics of a pressure-supported breath. In this example, the baseline pressure (ie, PEEP) is set at $5 \mathrm{~cm} \mathrm{H}_{2} \mathrm{O}$, and the pressure support is set at $15 \mathrm{~cm} \mathrm{H}_{2} \mathrm{O}$. The inspiratory pressure is triggered at point $\mathrm{A}$ by a patient effort, resulting in an airway pressure decrease. The rise to pressure (line $B$ ) is provided by the initial flow into the airway. If the initial flow is excessive, the initial pressure exceeds the set level (B1). If the initial flow is low, there is a slow rise to pressure (B2). The plateau of pressure support (line $C$ ) is maintained by control of flow. A smooth plateau indicates appropriate flow responsiveness to patient demand. Termination of pressure support occurs at point $D$ and should coincide with the end of neural inspiration. If breath termination is delayed, the patient may actively exhale (the pressure rises above the plateau) (D1). If breath termination is premature, the patient may have continued inspiratory efforts (D2). (Adapted from Reference 18, with permission.)

\section{Flow Cycling}

While other forms of cycling are essential and inherent to mechanical ventilation, flow cycling has received the most attention and has been the subject of numerous clinical investigations. ${ }^{9-16}$ The reason for multiple studies of flow cycling is attributed to the universal adoption of spontaneous breathing modes such as pressure-support ventilation (PSV). ${ }^{17}$ During PSV the patient both triggers and cycles the breath (Fig. 1). ${ }^{18,19}$ The algorithms used to cycle PSV breaths had traditionally been fixed at a certain percentage of peak inspiratory flow, meaning that when the patient's inspiratory flow decreases to a predetermined level, historically $25 \%$ of peak inspiratory flow, the breath would cycle into exhalation. For a given tidal volume, the expiratory flow waveform is determined by patient mechanics (ie, effort, resistance, and compliance) and thus varies considerably from patient to patient and from breath to breath. Therefore, a fixed cycling threshold percentage of peak flow will result in a wide range of flows at the moment of cycling, providing a sort of "one size fits all" strategy. Because of that fixed criterion and lack of adjustment to match cycling to variable patient conditions, 

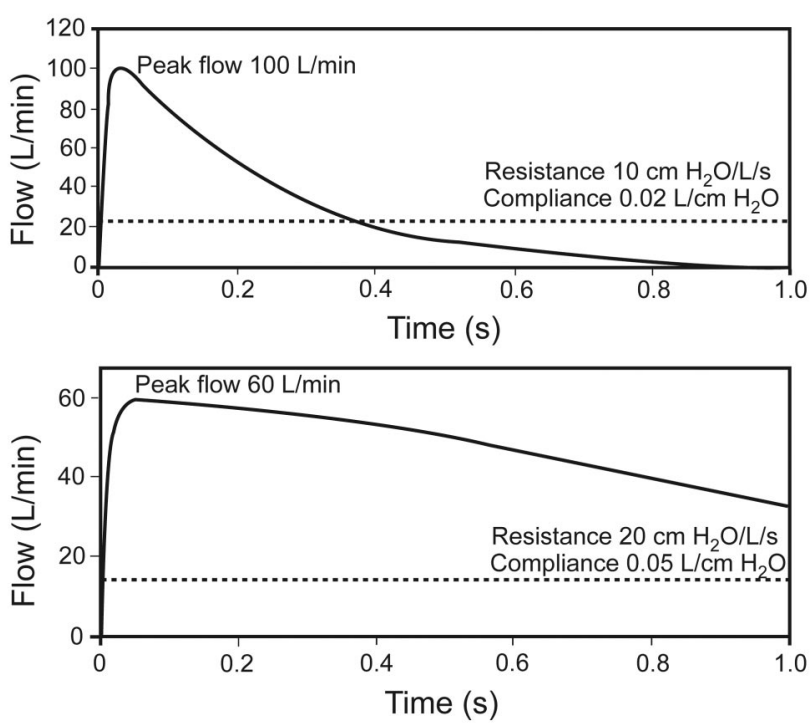

Fig. 2. Effect of respiratory mechanics on cycling of pressure support from inhalation to exhalation. Flow cycling is set at $25 \%$ of the peak flow, as illustrated by the broken line. The upper panel represents the respiratory mechanics of a patient with restrictive lung disease. The lower panel represents the respiratory mechanics of a patient with obstructive lung disease. In each case the neural inspiratory time is 1.0 second. The breath terminates prematurely in the patient with restrictive lung disease, but the breath is prolonged in the patient with obstructive lung disease. Also note that the peak flow is greater in restrictive lung disease, and the pressure decrease is more rapid in restrictive lung disease. (Adapted from Reference 19.)

large bodies of evidence on the topic were not available until recently. However, it has been recognized that this fixed cycling criterion (percent flow) is influenced by many factors, including time constants of the respiratory system, the level of pressure support, and possible remaining inspiratory effort at the end of the breath (Fig. 2).

Another consideration for cycling criteria is the presence of air leaks from, for instance, bronchopleural fistula, cuffless airway, partially inflated endotracheal tube cuff, or mask during noninvasive ventilation. If the leak exceeds the set cycling flow, either active exhalation or a prolonged inspiratory time will occur.

After numerous accounts of expiratory asynchrony, mechanical ventilator manufacturers created features that allow adjustment of flow cycling. The PSV flow-cycle threshold is adjustable on current mechanical ventilators, and the flow-cycling setting has various trade names (Table 1), though none of them are referred to as "flowcycle threshold," which adds to the confusion of terminology related to mechanical ventilators. The flow-cycling criterion is different on various ventilators, with a range of $1-80 \%$ of peak flow. Adjustments in flow cycling can dramatically alter the graphics waveforms (Fig. 3) and the airway and esophageal pressure, reflect-
Table 1. Flow Cycle Criteria and Brand Names on Some Common Mechanical Ventilators

\begin{tabular}{lcl}
\hline \hline \multicolumn{1}{c}{ Ventilator } & $\begin{array}{c}\text { Flow Cycling } \\
\text { Range (\%) }\end{array}$ & \multicolumn{1}{c}{ Brand Name } \\
\hline GE Engström Carestation & $5-50$ & EndFlow \\
Newport E500 & $5-55$ & Expiratory Threshold \\
Puritan Bennett 840 & $1-45$ & Esens \\
Respironics V200 & $10-80$ & Ecycle \\
Maquet Servo-i & $10-70$ & Inspiratory Cycle Off \\
Hamilton G5 & $5-70$ & Expiratory Trigger Sensitivity \\
Dräger Evita XL & 25 & (none) \\
Carefusion Avea & $5-45$ & PSV Cycle \\
\hline
\end{tabular}

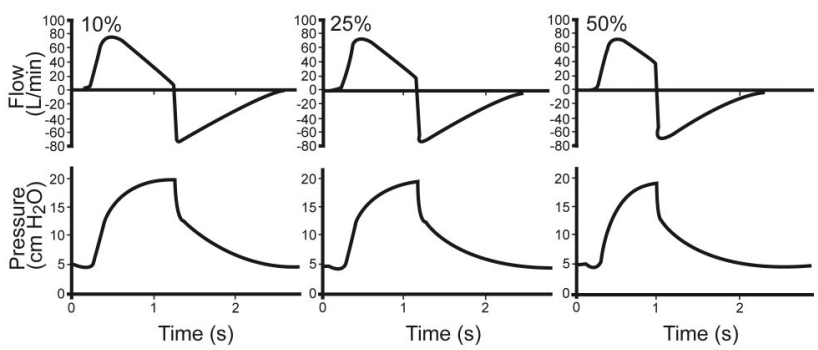

Fig. 3. Lung model waveforms with flow cycling at 10\%, 25\%, and $50 \%$, with a Puritan Bennett 840 ventilator set on pressure support $15 \mathrm{~cm} \mathrm{H} \mathrm{H}_{2} \mathrm{O}$ and PEEP of $5 \mathrm{~cm} \mathrm{H}_{2} \mathrm{O}$. The lung model settings were resistance $5 \mathrm{~cm} \mathrm{H} \mathrm{O} / \mathrm{L} / \mathrm{s}$, compliance $0.05 \mathrm{~L} / \mathrm{cm} \mathrm{H}_{2} \mathrm{O}$. (Adapted from Reference 19.)

ing patient effort. This may be confusing to the bedside clinician, as many of the other settings have universal labels, such as tidal volume, PEEP, and $\mathrm{F}_{\mathrm{IO}_{2}}$, but cycling is unique to each device. To provide safe and consistent care, it is imperative to patient-ventilator interaction for clinicians to be familiar with and fully understand the cycling operation for each ventilator. Although there is no consensus on the absolute setting of the flow-cycling criterion, it should be adjusted to enhance patient comfort and synchrony. As with all other mechanical ventilator settings, it is paramount to match the appropriate flow-cycling criterion with the specific underlying pathophysiology. Patients with obstructive disease (asthma or COPD) require different cycling criteria than those with acute lung injury or other forms of lung impairment.

Optimal synchrony is achieved by adjusting the flowcycling setting while observing patient effort and interpreting the mechanical ventilator graphic waveforms. ${ }^{7,19,20}$ This requires the clinician to adjust the flow-cycle setting and then reexamine the patient and ventilator waveforms. Currently there are no evidencebased guidelines on adjusting cycling. However, available evidence suggests cycling-criterion adjustments of $\pm 5 \%$, while observing the ventilator waveforms, pa- 
tient effort, and tidal volume. A suggested algorithm for optimizing cycling is:

1. Change to PSV mode.

2. While observing the graphics and the patient, adjust the cycling criterion to avoid a pressure spike at endexhalation and double triggering.

3. Avoid premature termination of the breath.

4. Observe the patient for signs of asynchrony.

The optimal cycling setting may change over the course of the patient's mechanical ventilation, so the cycling criterion must be evaluated frequently and as the patient's condition changes.

Advanced software designed to eliminate expiratory asynchrony during PSV has been described by Du et al, ${ }^{15}$ and is based on a mathematical model that automatically adjusts the flow-cycling threshold based on data from previous breaths. ${ }^{12}$

\section{Premature Cycling}

Most scientific study of mechanical ventilation cycling focuses on delayed cycling. However, premature breath cycling may also have detrimental effects on patient-ventilator synchrony. Premature cycling is simply when the ventilator terminates the breath while the patient requires a longer inspiratory period. During premature cycling, inspiratory muscles continue to contract, causing the mechanical ventilator to sense a second effort, and possibly resulting in a second breath, commonly referred to as "stacking of breaths" or "double triggering." The consequence of this type of asynchrony may be decreased tidal volume, increased inspiratory load, and inaccurate display respiration of respiratory rate; more concerning is a tidal volume much higher that what is set, thus resulting in possible injurious volume.

Tokioka et al evaluated the effects of PSV cycling in patients recovering from acute lung injury, with flow-cycling at $1 \%, 5 \%, 20 \%, 35 \%$, and $45 \%$ of peak inspiratory flow. ${ }^{21}$ The main finding was that the higher flow-cycling percentages resulted in premature breath termination, double-triggering, lower tidal volumes, higher respiratory rate, and higher work of breathing.

\section{Delayed Cycling}

Optimal assistance of spontaneous breaths would require cycling to correspond to the end of the patient's neural inspiratory effort. The presence of active expiratory effort before the cycle criterion is met is termed "delayed cycling" (Fig. 4). Clinically, delayed cycling can be as subtle as graphical abnormalities to as extreme as a complete asynchrony requiring an increase in sedation medication.

Delayed cycling is typically described in patients with COPD, ${ }^{22-24}$ in whom the inspiratory flow reduction is less, due to dynamic hyperinflation, airways resistance, and lung

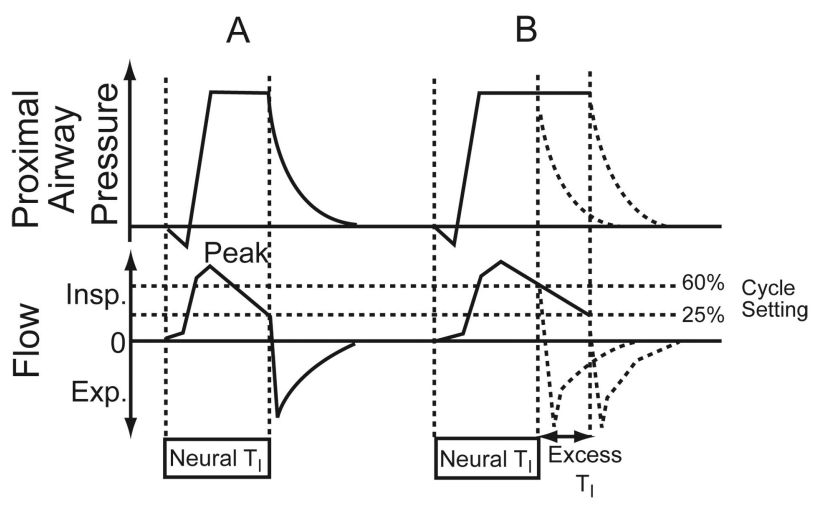

Fig. 4. Airway pressure and flow graphics illustrate delayed cycling. A: Normal respiratory mechanics. The cycle setting is $25 \%$ of peak inspiratory flow. Cycling is ideal, as indicated by the fact that the inspiratory flow decreases to the $25 \%$ cycling level at the end of the patient's neural inspiratory time $\left(T_{1}\right)$. B: Obstructive respiratory mechanics. The change in the inspiratory flow curve leads to the $25 \%$ level being reached later, well after the end of the neural $T_{1}$. The duration of delayed cycling is represented by the excess $T_{1}$. Increasing the cycle setting to $60 \%$ of peak inspiratory flow corrects this problem, and cycling occurs at the end of neural $\mathrm{T}_{1}$. Insp $=$ inspiration. Exp $=$ expiration. (Adapted from Reference 22, with permission BioMed Central.)

compliance. This abnormal prolongation of inspiration reduces the time available for the expiratory flow, increasing the dynamic hyperinflation and the patient's work of breathing (Fig. 5). ${ }^{25}$

The adverse effects of delayed cycling are summarized in Figure 6. While delayed cycling has many negative ramifications, intrinsic PEEP may be the most deleterious. In addition to expiratory synchrony, intrinsic PEEP, in some form of air trapping, may also be the cause of trigger asynchrony. The patient will require various levels of added effort to inspire through the intrinsic PEEP to reach the triggering threshold and activate the breath.

\section{Expiratory Asynchrony}

Expiratory asynchrony can be identified as the delay in the relaxation of the expiratory-muscle activity prior to the next mechanical inspiration. Simply, there is an overlap between expiratory and inspiratory activity. Ideally this would be identified with neural measurements, but these measurements are not readily available, and so clinicians must instead rely on careful analysis of ventilator graphic waveforms and patient assessment (Fig. 7). ${ }^{24,26-29}$

In the condition of expiratory asynchrony, the termination of the ventilator flow occurs either before or after the patient stops the inspiratory effort. Expiratory asynchrony causes patient discomfort and unnecessary inspiratory and expiratory patient work. Tassaux et al studied 10 intubated COPD patients with flow-cycle settings of $10 \%, 25 \%, 50 \%$, 

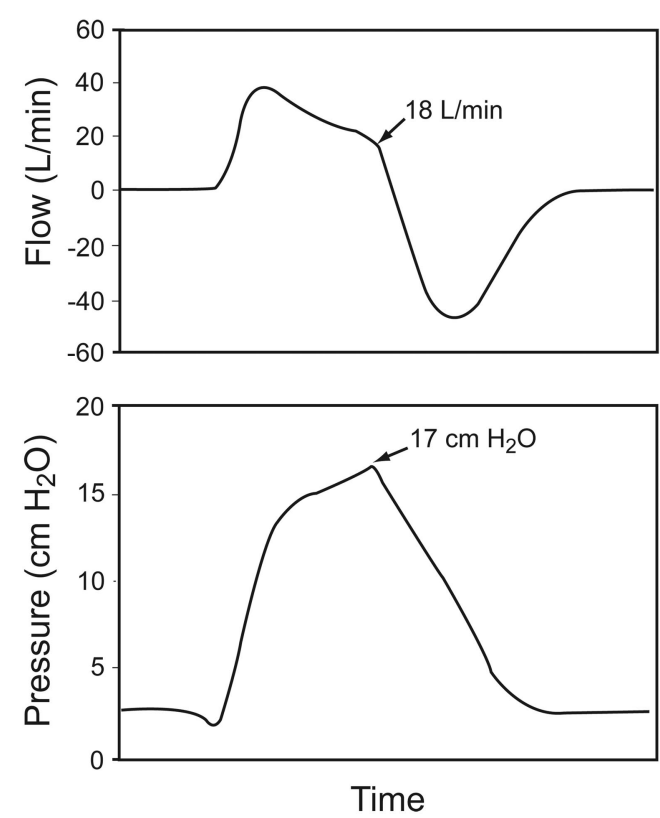

Fig. 5. An example of delayed cycling during pressure-support ventilation of a patient with COPD, on a Puritan Bennett 7200 ventilator, which has a flow-termination of $5 \mathrm{~L} /$ min during pressure-support ventilation at $12 \mathrm{~cm} \mathrm{H}_{2} \mathrm{O}$. The ventilator cycles at $18 \mathrm{~L} / \mathrm{min}$. The pressure increase above the set pressure-support level causes the ventilator to pressure-cycle in response to the patient's active exhalation. (Adapted from Reference 25.)

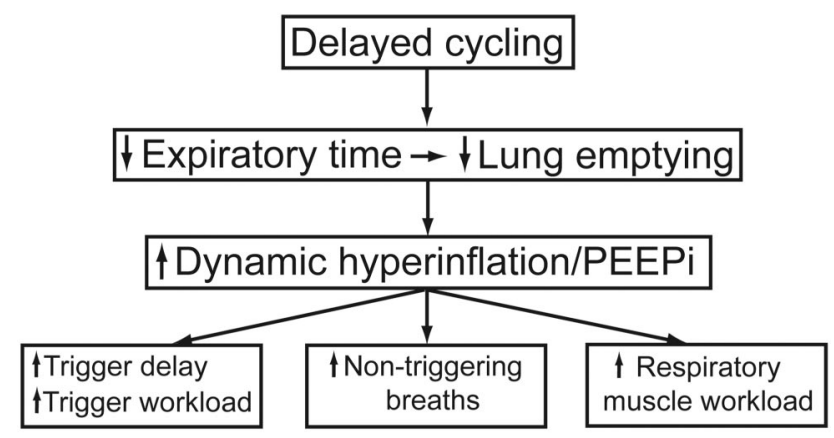

Fig. 6. Consequences of delayed cycling. PEEPi = intrinsic PEEP. (Adapted from Reference 22, with permission BioMed Central.)

and $70 \%$ of peak inspiratory flow. ${ }^{16}$ Increasing the flowcycle setting to greater than $25 \%$ of peak inspiratory flow decreased the duration of pressurization; reduced delayed cycling without causing premature cycling; and reduced intrinsic PEEP, trigger delay, the magnitude of inspiratory effort required to trigger the ventilator, and the number of nontriggered breaths. Conversely, decreasing the cycling criterion to less than $25 \%$ worsened patient-ventilator asynchrony. This clearly demonstrated the need for continuous monitoring and adjustment of the flow-cycling criterion to optimize patient-ventilator interaction.

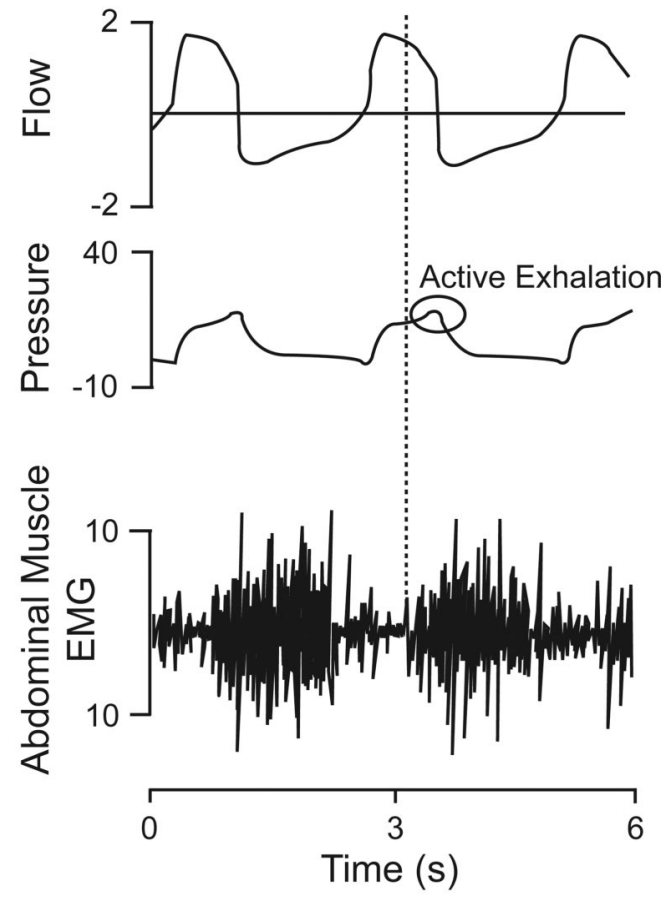

Fig. 7. Flow, airway pressure, and transversus abdominis electromyogram (EMG) waveforms from a mechanically ventilated patient with COPD receiving pressure-support ventilation at $20 \mathrm{~cm} \mathrm{H}_{2} \mathrm{O}$. The onset of expiratory muscle activity (vertical dotted line) occurred when mechanical inflation was only partly completed, as indicated by the onset of expiratory muscle activity. Active exhalation caused an increase in airway pressure at end-exhalation, causing the ventilator to pressure-cycle rather than flow-cycle. (Adapted from Reference 29, with permission.)

\section{Summary}

Substantial progress has been made in the understanding of patient-ventilator interaction. It has become increasingly recognized that cycling is an important determinant of optimal patient-ventilator synchrony. Cycling of the mechanical breath has gained the attention of both ventilator manufacturers and clinicians. There have been advances in technology, monitoring, and assessment, and, in light of the increasing use of PSV, this heightened understanding has become crucial in the everyday clinical management of mechanically ventilated patients. Proper adjustment of cycling is crucial to improve patient-ventilator synchrony and decrease work of breathing. Mechanical ventilator design in the future should include some form of automation control for cycling, to meet changing patient conditions.

The various key phases and pitfalls of a ventilator-assisted breath should be understood to reduce unnecessary respiratory muscle work load and improve patient comfort. Special attention should be paid to patients undergoing mechanical ventilation in problems encountered in intubated patients. 


\section{REFERENCES}

1. Tobin MJ, Jubran A, Laghi F. Patient-ventilator interaction. Am J Respir Crit Care Med 2001;163(5):1059-1063.

2. Kondili E, Prinianakis G, Georgopoulos D. Patient-ventilator interaction. Br J Anaesth 2003;91(1):106-119.

3. Thille AW, Rodriguez P, Cabello B, Lellouche F, Brochard L. Patient-ventilator asynchrony during mechanical ventilation: prevalence and risk factors. Intensive Care Med 2006;32(10):1515-1522.

4. Tobin MJ, Jubran A, Laghi F. Respiratory muscle dysfunction in mechanically ventilated patients. Mol Cell Biochem 1998;179(1-2):87-98.

5. Sassoon CS, Foster GT. Patient-ventilator asynchrony. Curr Opin Crit Care 2001;7(1):28-33.

6. Younes M, Kun J, Webster K, Roberts D. Response of ventilatordependent patients to delayed opening of exhalation valve. Am J Respir Crit Care Med 2002;166(1):21-30.

7. Prinianakis G, Kondili E, Georgopoulos D. Effects of the flow waveform method of triggering and cycling on patient-ventilator interaction during pressure support. Intensive Care Med 2003;29(11):1950-1959.

8. Chatburn RL. Classification of ventilator modes: update and proposal for implementation. Respir Care 2007;52(3):301-323.

9. Du HL, Ohtsuji M, Shigeta M, Chao DC, Sasaki K, Usuda Y, Yamada Y. Expiratory asynchrony in proportional assist ventilation. Am J Respir Crit Care Med 2002;165(7):972-977.

10. Du HL, Yamada Y. Expiratory asynchrony. Respir Care Clin 2005; 11(2):265-280

11. Spahija J, de Marchie M, Albert M, Bellemare P, Delisle S, Beck J, Sinderby C. Patient-ventilator interaction during pressure support ventilation and neurally adjusted ventilatory assist. Crit Care Med 2010;38(2):518-526.

12. Yamada Y, Du HL. Analysis of the mechanisms of expiratory asynchrony in pressure support ventilation: a mathematical approach. J Appl Physiol 2000;(88):2143-2150.

13. Manning HL, Molinary EJ, Leiter JC. Effect of inspiratory flow rate on respiratory sensation and pattern of breathing. Am J Respir Crit Care Med 1995;151(3 Pt 1):751-757.

14. Chiumello D, Pelosi P, Taccone P, Slutsky A, Gattinoni L. Effect of different inspiratory rise time and cycling off criteria during pressuresupport ventilation in patients recovering from acute lung injury. Crit Care Med 2003;31(11):2604-2610.

15. Du HL, Amato M, Yamada Y. Automation of expiratory trigger in pressure support ventilation. Respir Care Clin North Am 2001;7(3): 503-517.
16. Tassaux D, Michotte JB, Gainnier M, Gratadour P, Fonseca S, Jolliet P. Expiratory trigger setting in pressure support ventilation: from mathematical model to bedside. Crit Care Med 2004;32(9):1844-1850.

17. Esteban A, Anzueto A, Alia I, Gordo F, Apezteguia C, Palizas F, et al; Mechanical Ventilation International Study Group. How is mechanical ventilation employed in the Intensive Care Unit? An international utilization review. Am J Respir Crit Care Med 2000;161(5):1450-1458.

18. MacIntyre N, Nishimura M, Usada Y, Tokioka H, Takezawa J, Shimada Y. The Nagoya conference on system design and patientventilator interactions during pressure support ventilation. Chest 1990; 97(6): 1463-1466.

19. Hess DR. Ventilator waveforms and the physiology of pressure support ventilation. Respir Care 2005;50(2):166-183.

20. Nilsestuen JO, Hargett KD. Using ventilator graphics to identify patient-ventilator asynchrony. Respir Care 2005;50(2):202-234.

21. Tokioka H, Tanaka T, Ishizu T, Fukushima T, Iwaki T, Nakamura Y, Kosogabe Y. The effect of breath termination criterion on breathing patterns and the work of breathing during pressure support ventilation. Anesth Analg 2001;92(1):161-165.

22. Jolliet P, Tassaux D. Clinical review: patient-ventilator interaction in chronic obstructive pulmonary disease. Critical Care 2006;10:236-241.

23. Branson RD. Functional principles of positive pressure ventilators: implications for patient-ventilator interaction. Respir Care Clin 2005; 11(2):119-145.

24. Chiumello D, Polli F, Tallarini F, Chierichetti M, Motta G, Azzari S, et al. The effect of different cycling off criteria and PEEP during pressure support ventilation in patients with chronic obstructive pulmonary disease. Crit Care Med 2007;35(11):2547-2552.

25. Branson, RD, Campbell RS. Pressure support ventilation, patientventilator synchrony, and ventilator algorithms (editorial). Respir Care 1998;43(12):1045-1047.

26. Calderini E, Confalonieri M, Puccio PG, Francavilla N, Stella L, Gregoretti C. Patient-ventilator asynchrony during non-invasive ventilation: the role of expiratory trigger. Intensive Care Med 1999; 25(6):662-667.

27. Lessard MR, Lofaso F, Brochard L. Expiratory muscle activity in creases intrinsic positive end expiratory pressure independently of dynamic hyperinflation in mechanically ventilated patients. Am J Respir Crit Care Med 1995;151(2):562-569.

28. Tassaux D, Gainnier M, Battisti A, Jolliet P. Impact of expiratory trigger setting on delayed cycling and inspiratory muscle workload. Am J Respir Crit Care Med 2005;172(10):1283-1289.

29. Parthasarathy S, Jubran A, Tobin MJ. Cycling of inspiratory and expiratory muscle groups with the ventilator in airflow limitation. Am J Respir Crit Care Med 1998;158(5 Pt 1):1471-1478.

\section{Discussion}

Sassoon: Has there been a study to compare the Newport's automatic cycling to that of other ventilators?

Gentile: I looked for papers on that, including in the Japanese literature, and didn't find any. Does anyone else have any information?

Kacmarek: We had an abstract at the 2008 AARC [American Association for Respiratory Care] meeting, on research in which we did just that, with an ASL 5000 lung model. ${ }^{1}$ The Newport automated approach was as good as our fine-tuning of pressure support with other ventilators. The triggering, rise time, and termination criteria were set as best we could, and the Newport's automated approach was pretty much equivalent to what we could do manually.

1. Marchese AD, Suleymanci D, Chipman DW, Villar J, Kacmarek RM. Triggering and initial gas delivery of current ICU ventilators (abstract). Respir Care 2008;53(11):1508.
Epstein: Can you describe the mechanism?

Kacmarek: It's a mathematical model that looks at resistance and the time constant for flow deceleration.

Branson: If I remember right, it measures the time constant and, I think, it splits the length of the time constant. So, if you have a prolonged time constant, it starts you at $50 \%$ of the initial peak flow rate, and then it continues to measure the time constant and in- 
creases or decreases it every couple breaths by $5 \%$, I think. At the same time, it looks at that last 80 milliseconds of inspiration, and if the pressure rises above the set pressure support, then it further backs it off. I think the maximum may only be $60 \%$.

Epstein: I think it analyzes the end of the airway pressure tracing. If that rises about $0.8 \mathrm{~cm} \mathrm{H}_{2} \mathrm{O}$, it changes the cycle criterion to shorten the mechanical inspiration, whereas if it's less than a $0.2 \mathrm{~cm} \mathrm{H}_{2} \mathrm{O}$ rise, it lengthens the mechanical inspiration.

Kacmarek: It also looks at the rise time.

Gentile: Yes, it looks at the inspiratory side.

Branson: I think it's that they're separate, but that ventilator automatically adjusts the rise time and the cycle.

\section{Gentile: Correct.}

Chatburn: Do you know how they estimate the time constant? Is it the inspiratory or expiratory time constant?

Branson: I believe it's inspiratory.

Chatburn: How do they get it?

Branson: I think it has a flow sensor at the airway.

Kacmarek: I think it's actually the expiratory time constant.

Branson: Is it? I'll take your word on it; expiratory makes more sense.

Kacmarek: They look at passive decay during the expiratory phase.

Gentile: Their Web site clearly states that it's patented.
Younes:* We know from the PAV [proportional assist ventilation] experience that when you synchronize the end of the cycle, you automatically eliminate pretty much all ineffective efforts and you get one-to-one relationships between the patient rate and the respiratory rate. So improving cycling would automatically lead to rapid shallow breathing in patients who have an intrinsic high respiratory rate, independent of the level of assist. Before we jump on improving cycling, we have to struggle with the idea that we have to accept rapid shallow breathing as a physiologic response.

What do you say about that? Are you willing to accept that if you synchronize the end of expiration properly and the patient has a respiratory rate of 40 breaths a minute, he's going to drop his tidal volume to match his ventilatory demand. Are you willing to accept that? Because that's the tradeoff.

Gentile: The question is, what's the lesser evil? Does a respiratory rate of 40 breaths a minute lead to intrinsic PEEP?

Younes: No, PEEP isn't affected.

Gentile: Right, because a lot of time on a ventilator you'll have intrinsic PEEP associated with a patient with a high respiratory rate because the patient can't exhale completely, even with an active expiratory valve.

Younes: If you don't lower tidal volume but you have a smaller tidal volume, basically the intrinsic PEEP is primarily related to the minute ventilation in a given patient. And minute ventilation doesn't change, it's just that they switch to a synchronous rate of 40 breaths a minute with tidal volume half of what it was at 20 breaths a

\footnotetext{
* Magdy Younes MD FRCP(C) PhD, Department of Medicine, University of Manitoba, Winnipeg, Manitoba, Canada.
}

minute, but the intrinsic PEEP doesn't change. But is that an acceptable solution to the problem?

Gentile: A rate of 40 is probably going to make a lot of people nervous.

Kacmarek: Magdy, that doesn't always happen; even when we switch to PAV from ineffective pressure support, we don't always see the respiratory rate going that high.

Younes: No, but there is a subset of patients who have a high intrinsic respiratory rate, and they will drop their tidal volume if the ventilator rate tracks their own high intrinsic rate. I agree with you that the majority of patients are fine.

Kacmarek: I took what you said to mean that any time you correct the inspiratory cycling, you end up with a rapid shallow breathing pattern.

Younes: No: you'd end up with the patient's real respiratory rate, and the tidal volume will adjust itself, but sometimes that respiratory rate is very high.

Kacmarek: I agree. That's a big issue with accepting PAV and NAVA [neurally adjusted ventilatory assist]. Clinicians must accept the patient's innate ventilatory pattern, which is frequently very different from what clinicians have in their mind as the ideal pattern for that patient. What we don't know is who knows best? Does the patient know best or do we know best? I'd bet on the patient the vast majority of the time.

Younes: If there's no distress.

Kacmarek: Exactly.

Gentile: Doesn't that depend on the percent gain setting on both PAV and NAVA?

Younes: No. 
Gentile: So if you set a higher gain, can you slow them down?

Younes: The breathing pattern on PAV is independent of the percent assist.

Kallet: I'm glad you added the point about the patient not being in distress, because I think you have to take all of this within a specific context. The 2 archetypes are, someone in distress who has COPD, versus someone with ALI [acute lung injury]. In either situation I'm not so sure the patient's native pattern is the best. When an organism is in distress, the mechanics are altered, gas exchange is highly abnormal, and respiratory muscle function is pushed to the limit. The organism is trying to do whatever it can to survive and prevent imminent collapse, so the breathing pattern may not be the "wisdom of the body," but just the organism making a "last-ditch effort" at survival. In that case, the clinician may be better than the patient.

In patients with respiratory rates of 50 or 60 breaths a minute, I would not let an acutely ill hypotensive patient with COPD and respiratory acidosis breathe at 50 or 60 breaths a minute, and I sure as hell wouldn't want the ventilator to capture that. I think there always has to be clinician involvement in overseeing any type of closed-loop ventilation to make sure that those problems don't occur.

Younes: There is a misconception that a high intrinsic respiratory rate is always a sign of distress. It is obviously a sign of distress, because when people are in distress, they increase their respiratory rate. But if you study the control of breathing, there are so many other reasons for an increase in respiratory rate other than distress.

The best proof in an ICU patient is if you take a patient who has a high intrinsic rate on low pressure support or PAV and put the catheter in and measure their diaphragm excursions and then give them more and more pressure support, you'll see their diaphragm pressure amplitude go down20, 15, 10, 5, 4-until they're almost apneic, and they're breathing at exactly the same rate. So how can that rate be a manifestation of distress? You've helped them as much as you could, and their efforts now are so small but it's the same rate, so obviously in that patient the high respiratory rate is not a manifestation of distress, but of other chemicals and neuromodulators.

Kallet: I agree. I think tachypnea as a manifestation of someone who's recovering from illness is not the same as in someone who is unstable and in distress. I have a lot more latitude with tachypnea in patients who are recovering and trying to wean than in someone who is getting worse. I think we're actually agreeing.

Chatburn: As long as we're talking about whether a high respiratory rate is "normal" or natural, I'll point out that animals pant all the time and they seem to do quite well. I looked at the veterinary literature and found nothing about panting being associated with volume delivery or lung mechanics: it's all about heat exchange.

Pierson: I think the whole field of mechanical ventilation suffers from widespread terminologic gobbledygook, and I'm afraid we're seeing some of it today, or at least it's coming across that way to me. This is not germane to what we were just talking about, but in general and for the remainder of the conference, is asynchrony the same as dyssynchrony? Are they synonyms?

Epstein: For our purposes, I think you should consider them synonyms. You're absolutely right: numerous terms are used to describe the same thing, and 2 authors might use the same term to describe slightly different things. I'm not sure "dyssynchrony" is in the Oxford English Dictionary.
Branson: It's not.

Epstein: But it was coined a number of years ago.

Gentile: They're both in PubMed.

Epstein: It's like atelectrauma.

Pierson: So we would kind of agree that when you went through your list of the different manifestations and different forms of this-

Epstein: I was using them interchangeably.

Pierson: OK, and you're using them specifically.

Epstein: And I was merely quoting the literature, because they're used interchangeably by authors.

Pierson: And can we agree that "cycling" and "expiratory triggering" and "breath termination" are the same thing?

Gentile: Yes.

Pierson: Exactly the same? Synonymous?

Gentile: Right. The papers and chapters use "cycling" as the heading but they use many different words for the same thing.

Pierson: I hope someone someday will come up with a better term than rise time. It's anachronistic, the bigger your rise time, the shorter the time you have.

Gentile: Some people call it pressure slope.

Branson: Mike, I just looked it up, and the Newport algorithm allows a change from $10 \%$ to $55 \%$ in the flex cycle automated selection of the percentage of peak inspiratory flow that terminates the breath. 
Prinianakis' study ${ }^{1}$ said that the little pressure spike at the end of inspiration is actually respiratory muscle relaxation at the end of inspiration, and is not associated always with expiratory muscle activity.

1. Prinianakis G, Plataki M, Kondili E, Klimathianaki M, Vaporidi K, Georgopoulos D. Effects of relaxation of inspiratory muscles on ventilator pressure during pressure support. Intensive Care Med 2008;34(1): 707-4.

Younes: It's actually rarely associated with the expiratory muscles. It is just the relaxation of inspiratory muscles.

Epstein: And that's the basis for NAVA, right? Using $80 \%$ of the EMG [electromyogram] signal to cycle?

Branson: Correct. NAVA uses $80 \%$ of the EMG cycle, which is totally different. Not only can't you compare $80 \%$ to $5 \%$-it's like 80 pesos versus $\$ 5$-it's not even the same measurement or the same signal, so matching them up-even if you put both of them at 5\% somehow-still wouldn't mean the same thing.

Chatburn: Magdy, you wrote an editorial $^{1}$ about why the pressure rises at the end.

1. Younes M. Why does airway pressure rise sometimes near the end of inflation during pressure support? Intensive Care Med 2008; 34(1):1-3

Younes: Yes. I fully agree that most of the time that little spike-provided it's not excessive-is relaxation of the inspiratory muscles. The pressure is returning. If you look at the pleural pressure and imagine what happens to it in a fast breath, it goes up and then it comes down. When you add an inspiratory effort, it brings it down, but when the effort stops, it wants to go back up to where it would have been if it were passive, and the ventilator cannot adjust to that very quickly, so it rises temporarily. It just means the patient's inspiratory effort is strong.

Branson: Magdy, if the ventilator is supposed to cycle off at $5 \%$ but that pressure rise causes it to cycle off at $40 \%$, because now it becomes a pressure-cycled breath instead of a flowcycled breath, can I assume at that time that it's just muscle relaxation, or is it expiratory activity?

Younes: The default conclusion is that it's inspiratory muscle relaxation but that the patient is making a big inspiratory effort. Fighting the ventilator, which is expiratory activity, is usually a behavioral response: it is not a breath-by-breath kind of thing. Usually the reflexive expiratory activation happens at the end of expiration: not early on. So when they're fighting, it's a behavioral response, and it is very different from breath to breath. That's how you can tell whether it's expiratory fighting or just relaxation. If it's a big spike and reproducible from breath to breath, and there is not much time between when the spike starts and when the ventilator cycles off, that is inspiratory muscle relaxation. But if it's variable and there is a big delay, then you can assume it's behavioral and the patient is fighting.

Kacmarek: Isn't it somewhat determined by the pathology? With COPD patients I can palpate their abdominal muscles contracting at the same time that they're transitioning to the expi- ratory phase - not at the end of expiration, but at the beginning of the expiratory phase. It coincides with that spike.

Younes: You have to be careful, Bob. In those patients the inspiratory phase of the ventilator can go through the whole expiratory phase of the patient, so in those patients when you have so much expiratory asynchrony or delayed cycling, yes. But we're not talking about that: we're talking about regular pressure-support ventilation breaths.

Kacmarek: In patients without COPD, then, you have to be cautious in interpreting that bump, but in patients with COPD - at least the ones I've looked at carefully-almost always it seems to be associated with active exhalation effort prior to the ventilator converting to the expiratory phase.

Younes: But it's always in association with very delayed cycling.

Kacmarek: And a large tidal volume.

\section{Younes: Right.}

Gentile: Although we separated them out, Catherine [Sassoon] also did a very good job of pointing out that inspiration and expiration are very intricately linked. Triggering and cycling are linked, and we have to keep that in mind when interpreting the graphics and treating these patients.

1. Sassoon CSH. Triggering of the ventilator in patient-ventilator interactions. Respir Care 2011;56(1):39-48; discussion 49-51.

This article is approved for Continuing Respiratory Care Education credit. For information and to obtain your CRCE

(free to AARC members) visit

RCJournal.com

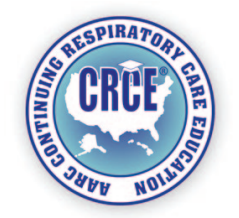

